\title{
Erratum to: High-pressure and high-temperature deformation experiments on polycrystalline wadsleyite using the rotational Drickamer apparatus
}

\author{
Robert Farla $^{1,2} \cdot$ George Amulele $^{1} \cdot$ Jennifer Girard $^{1} \cdot$ Nobuyoshi Miyajima $^{2} \cdot$ \\ Shun-ichiro Karato ${ }^{1}$
}

Published online: 14 February 2017

(C) Springer-Verlag Berlin Heidelberg 2017

Erratum to: Phys Chem Minerals (2015) 42:541-558

DOI 10.1007/s00269-015-0742-0

In the original publication of the article, the $y$-axis title in both panels in Fig. 16 displays an incorrect unit of stress (MPa). The correct unit is GPa as shown in the reproduced figure below.

(A)

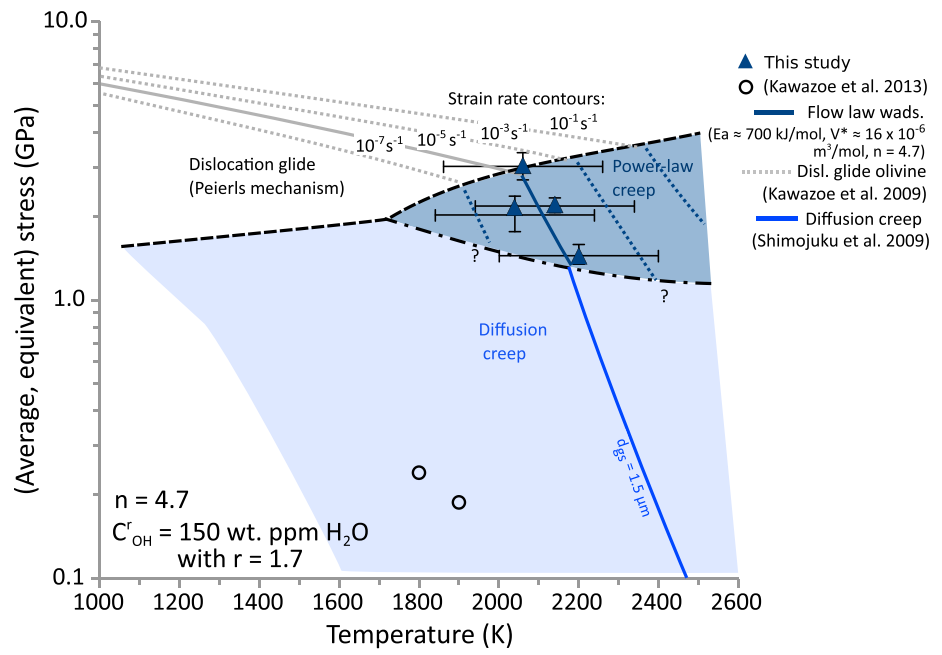

(B)

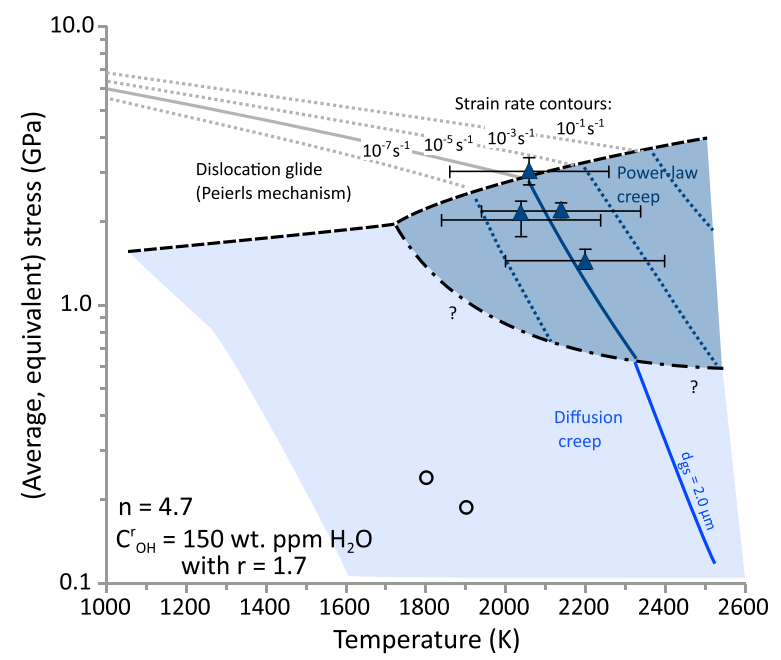

The online version of the original article can be found under doi:10.1007/s00269-015-0742-0.

Robert Farla

robert.farla@uni-bayreuth.de

1 Department of Geology and Geophysics, Yale University, New Haven, CT 06511, USA

2 Bayerisches Geoinstitut, Universität Bayreuth, Universitäts str. 30, 95447 Bayreuth, Germany 